\title{
The histocompatibility antigen in asbestos related disease
}

\author{
N Al Jarad, S Uthayakumar, E J Buckland, T S Green, J Ord, A C Newland, R M Rudd
}

\begin{abstract}
Thirty nine phenotypes of human leucocyte antigens (HLA)-A-B-DR and DQ were obtained from 99 asbestos workers (one woman and 98 men). Presence or absence of antinuclear antibodies and rheumatoid factor was determined in 91 of them. Workers were divided into five groups: asbestos workers with no apparent disease ( $A W ; n=17)$, diffuse benign pleural disease $(P D ; n=31)$, asbestosis $(A S ; n=24)$, asbestosis with lung cancer (ASCA; $n=14)$, and mesothelioma (M; $n=13)$. Compared with $A W$, several trends of differences of HLA antigen prevalence were found in patients with asbestos related disease, but these did not achieve statistical significance when $p$ was corrected $\left(p_{\text {corr }}\right)$ by number of analyses undertaken. Analysis of the results obtained in previous studies together with the results of this study showed that compared with AW, AS patients had decreased prevalence of HLA-DR5 ( $\left.p_{\text {corr }}<0.02\right)$. Reasons for the differences in results of previous studies and statistical methods commonly used to compare prevalences of HLA antigen are discussed.
\end{abstract}

It has been recognised that for a given cumulative exposure to asbestos dust, only a fraction of the exposed workers or animals develop one or more of the asbestos related diseases (benign pleural disease, asbestosis, mesothelioma, and lung cancer)..$^{1-3}$ The pathology of these diseases remains, however, controversial and the question "why is one person affected and not the man who works beside him?" remains unanswered.

Several studies have found alterations of humoral immunity in asbestos workers such as an increase in

The London Chest Hospital, Bonner Road, London E2 9JX

N Al Jarad, S Uthayakumar, A C Newland, R M Rudd

The Tissue Typing Unit, National Blood Transfusion Service, Crescent Drive, Brentwood, Essex CM15 8DP

E J Buckland, T S Green, J Ord circulating immunoglobulins, ${ }^{4-7}$ autoantibodies, ${ }^{48-10}$ and the complement components. ${ }^{5}$ Other studies have shown alterations of the lymphocyte subsets in the peripheral blood of asbestos workers with and without asbestosis. ${ }^{711}$

The fibrotic response to asbestos fibres could be genetically controlled; there is evidence from animal models that susceptibility to interstitial lung disease may be modified by immune and non-immune related genes. ${ }^{12}$ The human leucocyte antigen (HLA) has been linked with the immune response capability and close associations between some types of HLA and immunological conditions such as ankylosing spondylitis have been established. ${ }^{13}$ Several studies investigating associations between types of the HLA system and the occurrence of asbestosis have been published with inconsistent and sometimes conflicting results. ${ }^{14-21}$ All but one of these studies ${ }^{21}$ investigated the loci of the class I HLA (HLA-A-B-C) but not class II (HLA-DR, DQ, and DW). Recently a predisposition to development of idiopathic pulmonary fibrosis has been associated with one of the $B$ cell autoantigens, HLA-DR2. ${ }^{22}$

In this study we investigated class I and class II HLA in patients with different types of asbestos related disease and compared prevalences of HLAs between different groups using the data obtained in this and previously published studies.

\section{Patients and methods}

PATIENTS

We studied 98 white men and one white woman. Their mean age (range) was 59 (35-79). They were divided into five groups: asbestosis (AS; $n=24$ ), benign pleural disease (PD; $n=31)$, asbestosis and lung cancer (AS-CA; $n=14$ ), mesothelioma ( $M$; $\mathrm{n}=13$ ), and heavy asbestos exposure (two years or more) with no apparent disease ( $\mathrm{AW} ; \mathrm{n}=17$ ).

The diagnosis of asbestosis was made on the basis of a history of exposure to asbestos and shadowing on chest radiographs or high resolution computed tomography (HRCT) scans consistent with interstitial fibrosis. Asbestos bodies were detected in bronchoalveolar lavage fluid in the 11 patients in whom this was carried out.

Pleural disease and opacities suggestive of asbes- 
tosis were present on chest radiographs in all patients with lung cancer and asbestosis was confirmed by HRCT in four patients on whom this was performed. Pathological evidence of asbestosis was obtained from the two patients who underwent lobectomy. Histological confirmation of lung cancer was available for all patients with this disease and the cell types were small cell carcinoma (9), squamous cell carcinoma (4), and adenocarcinoma (one patient).

The diagnosis of mesothelioma was made on the basis of progressive chest pain, weight loss, and irregular pleural thickening with reduction of thoracic volume on chest radiographs. A histological diagnosis was obtained during life in 12 patients and at postmortem examination in one patient. Immunohistochemical stains were used as well as routine histological methods.

Patients classified as having benign pleural disease had plain chest radiographic evidence of pleural plaques or pleural thickening of at least $1 \mathrm{~b}$ grade on the International Labour Office (ILO) scale (length of pleural disease of more than a quarter of the lateral chest wall and maximum width more than $0.5 \mathrm{~cm})^{23}$ with or without involvement of the costophrenic angles. The diagnosis of interstitial fibrosis was ruled out on the basis of HRCT in all patients.

Those patients with past occupational exposure to asbestos and in whom the chest radiographs had shown no evidence of pleural disease and pulmonary opacities of less than $1 / 0$ were classified as AW. A diagnosis of asbestosis was ruled out on the basis of HRCT in all patients.

Exposure to asbestos was through lagging in 35, stripping asbestos in 16, loading and unloading asbestos in the shipyards (the docks) in 21 , building trade in 17 , and driving lorries occasionally loaded with asbestos in six patients. Non-occupational (domestic) asbestos exposure had occurred in four patients.

Thirty five patients were current smokers (smoked during the past three months), 52 were ex-smokers (smoked more than 20 lifetime packs and no cigarettes during the last three months), and 12 were nonsmokers (smoked less than 20 lifetime packs and no cigarettes during the last three months).

None of the patients had any clinical evidence of connective tissue disease, had received corticosteroids for at least three months, or had clinical symptoms of any viral disease during six weeks before the blood samples were taken. In patients with lung cancer, blood was withdrawn before any chemotherapy.

\section{METHODS}

\section{Blood withdrawal}

Blood $(50 \mathrm{ml})$ was withdrawn using a butterfly needle (gauge 19) and was divided into four tubes: $18 \mathrm{ml}$ of blood in $2 \mathrm{ml}$ of $3.8 \%$ citrate for HLA typing, $20 \mathrm{ml}$ with 200 units of preservative free heparin for lymphocyte separation, $2 \mathrm{ml}$ with ethylene diaminetetra-acetic acid for full blood cell count and differential white blood cell count, and $10 \mathrm{ml}$ untreated for detecting rheumatoid factor and antinuclear antibodies.

\section{HLA typing}

Thirty nine phenotypes of HLA-A-B, DR, and DQ were obtained from the fresh blood using a standard National Institute of Health 2-stage complement dependent microlymphocytotoxicity assay defining eight HLA-A and 17 HLA-B types according to methods described by Amos and Pool, ${ }^{24}$ Gibofsky $e t$ $a l^{25}$ and Terasaki ${ }^{26} ; \mathrm{DR}$ and DQ types were obtained using a similar method except that the target cells were $B$ lymphocytes isolated using metal beads coated with monoclonal anti-DR antibodies. ${ }^{27}$

\section{Rheumatoid factor and antinuclear antibodies}

Rheumatoid (antiglobulin) factors were measured by standard techniques; the differential agglutination tests $^{28}$ with sheep cells coated with rabbit globulin and the latex slide agglutination test ${ }^{29}$ with latex particles coated with human FII fraction. Rheumatoid factor was considered present when the latex test was positive at a serum dilution of $1 / 80$ or more.

Antinuclear factors were measured and titred by a standard double layer immunofluorescent technique. Cryostat sections of rat liver were used as a substrate, test sera were diluted $1: 10$, and fluorescein isothiocyanate conjugates of goat antihuman $\gamma$ globulin were applied. The immunoglobulin class of antinuclear factors was identified by the same immunofluorescent method using fluorescein isothiocyanate conjugates of monospecific horse antihuman IgM, IgG, and IgA (Red Cross blood transfusion, Amsterdam).

\section{STATISTICAL ANALYSIS}

Prevalences of HLA types were compared using Fisher's exact test or $\chi^{2}$ with Yates' correction. ${ }^{30}$ Values were corrected according to the Sidak-Dunn method $^{31} 32$ using the equation:

$$
\mathrm{p}_{\text {corr }}=1-(1-p)^{\mathrm{n}}
$$

where $\mathrm{p}_{\text {corr }}=\mathrm{p}$ corrected and $\mathrm{n}=$ number of analyses undertaken.

The strength of association between an HLA type and an asbestos related disease was estimated by calculating the relative risk (RR) as: incidence among asbestos related disease group/incidence among Aw group. The $95 \%$ confidence interval $(95 \% \mathrm{CI})$ of the RR was calculated using the $\chi^{2}$ value found in the significance test as follows:

$$
95 \% \mathrm{CI}=\mathbf{R R}^{(1 \pm 1 \cdot 96 / x)}
$$

Results were considered to be significant when $\mathrm{p}_{\text {corr }}$ $<0.05$. 


\begin{tabular}{|c|c|c|c|c|c|}
\hline & \multicolumn{5}{|l|}{ Group } \\
\hline & $A S(n=24)$ & $A S-C A(n=14)$ & $M(n=13)$ & $P D(n=31)$ & $A W(n=17)$ \\
\hline $\begin{array}{l}\text { Age (mean (SD)): } \\
\text { Pack-years (mean (SD)): } \\
\text { Duration of exposure to asbestos (mean (SD)): } \\
\text { Time since first exposure to asbestos (mean (SD)): }\end{array}$ & $\begin{array}{l}62(10 \cdot 6) \\
41 \dagger(28) \\
9 \cdot 3(7 \cdot 5) \\
38 \cdot 2(10 \cdot 8)\end{array}$ & $\begin{array}{l}66 \cdot 3(4 \cdot 5) \\
55^{\star} \ddagger(29) \\
10 \cdot 9(9 \cdot 1) \\
42(9 \cdot 7)\end{array}$ & $\begin{array}{l}58(6 \cdot 4) \\
32(26) \\
11(11) \\
34(6)\end{array}$ & $\begin{array}{l}55(10 \cdot 6) \\
23(17 \cdot 6) \\
10 \cdot 5(8 \cdot 6) \\
32 \cdot 6(11 \cdot 2)\end{array}$ & $\begin{array}{l}53(8 \cdot 5) \\
23(36) \\
12(6) \\
32(5 \cdot 5)\end{array}$ \\
\hline
\end{tabular}

${ }^{\star} \mathrm{p}<0.02$ compared with AW; $\nmid \mathrm{p}<0.0001$ compared with PD; $\ddagger \mathrm{p}<0.009$ compared with PD.

Table 2 A comparison of prevalence of HLA antigens in patients with asbestosis ( AS) and asbestos workers without any evidence of asbestosis $(A W)$ in several studies

\begin{tabular}{|c|c|c|c|c|c|c|c|c|}
\hline \multirow[b]{2}{*}{$H L A$} & \multicolumn{2}{|c|}{ Matej et al ${ }^{15}$} & \multicolumn{2}{|c|}{ Evans et al ${ }^{16}$} & \multicolumn{2}{|c|}{ Gregor et al ${ }^{17}$} & \multicolumn{2}{|c|}{ Huuskonen et al ${ }^{18}$} \\
\hline & $\begin{array}{l}A W \\
(n=112)\end{array}$ & $\begin{array}{l}A S \\
(n=22)\end{array}$ & $\begin{array}{l}A W \\
(n=27)\end{array}$ & $\begin{array}{l}A S \\
(n=37)\end{array}$ & $\begin{array}{l}A W \\
(n=80)\end{array}$ & $\begin{array}{l}A S \\
(n=92)\end{array}$ & $\begin{array}{l}A W \\
(n=37)\end{array}$ & $\begin{array}{l}A S \\
(n=64)\end{array}$ \\
\hline \multicolumn{9}{|l|}{ A: } \\
\hline 1 & 23 & 2 & 14 & 14 & 28 & 34 & 4 & 10 \\
\hline 2 & 53 & 14 & 16 & 18 & 38 & 48 & 21 & 39 \\
\hline 3 & 20 & 5 & 12 & 6 & 24 & 20 & 15 & 29 \\
\hline 9 & 26 & 3 & 5 & 10 & 10 & 10 & 8 & 14 \\
\hline 10 & 10 & 4 & 2 & 2 & 8 & 9 & 3 & 1 \\
\hline 11 & 11 & 2 & 5 & 4 & 11 & 15 & 2 & 4 \\
\hline 19 & - & - & - & - & 20 & 24 & 8 & 9 \\
\hline 28 & 4 & 0 & 2 & 4 & 8 & 7 & 6 & 10 \\
\hline \multicolumn{9}{|l|}{ B: } \\
\hline 5 & 14 & 0 & 6 & 2 & 11 & 11 & 2 & 8 \\
\hline 7 & 21 & 5 & 7 & 6 & 22 & 17 & 12 & 24 \\
\hline 8 & 19 & 2 & 10 & 10 & 20 & 31 & 4 & 11 \\
\hline 12 & 19 & 5 & 10 & 18 & 20 & 26 & 3 & 12 \\
\hline 13 & 6 & 3 & 2 & 2 & 3 & 6 & 1 & 3 \\
\hline 14 & 6 & 0 & 3 & 4 & 8 & 8 & 0 & 0 \\
\hline 15 & 6 & 1 & 0 & 1 & 10 & 11 & 6 & 16 \\
\hline 16 & 11 & 2 & 1 & 0 & 5 & 4 & 4 & 5 \\
\hline 17 & 11 & 2 & 3 & 5 & 7 & 9 & 0 & 0 \\
\hline 18 & 5 & 1 & 3 & 8 & 7 & 9 & 7 & 3 \\
\hline 21 & 5 & 0 & 2 & 2 & 3 & 7 & 0 & 0 \\
\hline 22 & 4 & 0 & 3 & 1 & 4 & 4 & 0 & 0 \\
\hline 27 & 11 & 6 & 3 & 2 & 4 & 11 & 11 & 9 \\
\hline 35 & 16 & 5 & - & - & 11 & 7 & 10 & 16 \\
\hline 37 & 13 & 3 & - & - & 2 & 3 & 0 & 1 \\
\hline $40^{\circ}$ & - & - & - & - & 12 & 9 & 9 & 11 \\
\hline W4 & - & - & - & - & - & - & 17 & 28 \\
\hline W6 & - & - & - & - & - & - & 36 & 57 \\
\hline
\end{tabular}

$\mathrm{AW}=$ asbestos workers with no evidence of asbestosis; $\mathrm{AS}=$ patients with asbestosis. Figures shown in parentheses are percentages. $-=$ An 8 HLA had not been typed in the correspondent study.

The study by Merchant $e t a l^{14}$ was not included in this comparison because the patients are included in the study by Gregore $e t$ al. ${ }^{15}$ Results are not significantly different in any study.

\section{Results}

Table 1 shows the demographic data. Duration of exposure to asbestos, or time since first exposure were not significantly different between the groups. Packyears of smoking were higher in the AS-CA than in the AW and PD groups ( $p<0.02$ and $p<0.0001$ respectively; Mann-Whitney $U$ test) and higher in the AS group than in the PD group ( $<<0.009$; Mann Whitney U test).

There were no significant differences in the frequencies of any HLA between the AW group and any of the study groups.

Presence of absence of antinuclear antibodies and rheumatoid factor was determined in 91 patients.
There was no difference in the prevalence of any HLA between patients in whom antinuclear antibodies were $(n=19)$ or were not $(n=72)$ detected. Similarly there were no differences in prevalence of any HLA in those patients in whom rheumatoid factor was present $(n=6)$ or absent $(n=85)$.

A review of publications showed that HLA A and $B$ antigens have been investigated in a total of 355 asbestos workers with no disease (AW) and 289 patients with asbestosis (AS) in studies by Matej et al,,$^{15}$ Evans et al, ${ }^{16}$ Gregor et al, ${ }^{17}$ Huuskonen et al,,$^{18}$ Vergnaud et $a l,{ }^{20}$ and the current study. The HLA DR 1-7 antigens have been investigated in $49 \mathrm{AW}$ and $64 \mathrm{AS}$ patients in the study by Begin et $a l^{21}$ and 
our current study combined. Compared with the AW group, the AS group had a decreased prevalence of HLA-DR5 $\left(p_{\text {corr }}<0.02\right)$. Tables 2 and 3 show the detailed results of our study and previous studies combined.

\section{Discussion}

We found no differences in prevalence of HLA antigens between $A W$ patients and patients with other types of asbestos related disease. Unlike the results of Merchant et $a l^{14}$ and Gregore $e t$ al ${ }^{17}$ who suggested an increase in HLA-B27 in AS patients, the prevalence of HLA-B27 was similar in all the study groups. The results of this study were also at variance with those by Huuskonen et al ${ }^{18}$ who found that HLA-B18 and B27 were higher in AW than AS patients. No difference was found in prevalence of the HLA-B12 antigen between AS and AW groups, unlike the results obtained by Evans et al ${ }^{16}$ who

\begin{tabular}{|c|c|c|c|c|c|c|c|}
\hline \multicolumn{2}{|c|}{ Vergnaud et al ${ }^{20}$} & \multicolumn{2}{|c|}{ The current study } & \multicolumn{4}{|c|}{ Total } \\
\hline $\begin{array}{l}A W \\
58\end{array}$ & $\begin{array}{l}A S \\
57\end{array}$ & $\begin{array}{l}A W \\
17\end{array}$ & $\begin{array}{l}A S \\
24\end{array}$ & $\begin{array}{l}A W \\
(n=\end{array}$ & 355) & $\begin{array}{l}A S \\
(n=\end{array}$ & 289) \\
\hline $\begin{array}{l}27 \\
27 \\
12 \\
- \\
5 \\
4 \\
3\end{array}$ & $\begin{array}{l}17 \\
26 \\
19 \\
- \\
7 \\
7 \\
4\end{array}$ & $\begin{array}{r}2 \\
10 \\
5 \\
5 \\
2 \\
2 \\
3 \\
3\end{array}$ & $\begin{array}{r}9 \\
12 \\
3 \\
2 \\
2 \\
2 \\
9 \\
1\end{array}$ & $\begin{array}{r}98 \\
165 \\
88 \\
54 \\
25 \\
36 \\
37 \\
26\end{array}$ & $\begin{array}{l}(28) \\
(46) \\
(25) \\
(18) \mathrm{a} \\
(8) \mathrm{a} \\
(10) \\
(17) \mathrm{b} \\
(7)\end{array}$ & $\begin{array}{r}86 \\
157 \\
82 \\
39 \\
18 \\
34 \\
49 \\
26\end{array}$ & $\begin{array}{l}(30) \\
(54) \\
(28) \\
(17) \mathbf{a}^{1} \\
(8) \mathbf{a}^{1} \\
(12) \\
(21) b^{\prime} \\
(10)\end{array}$ \\
\hline $\begin{array}{r}8 \\
15 \\
18 \\
18 \\
3 \\
14 \\
7 \\
6 \\
3 \\
4 \\
8 \\
5 \\
4 \\
-\end{array}$ & $\begin{array}{r}10 \\
13 \\
9 \\
16 \\
4 \\
0 \\
6 \\
-4 \\
8 \\
2 \\
10 \\
10 \\
6 \\
-\end{array}$ & $\begin{array}{r}5 \\
7 \\
0 \\
2 \\
0 \\
2 \\
1 \\
1 \\
1 \\
1 \\
1 \\
0 \\
2 \\
1 \\
1 \\
1 \\
11 \\
15\end{array}$ & $\begin{array}{r}2 \\
3 \\
3 \\
9 \\
1 \\
2 \\
2 \\
2 \\
4 \\
0 \\
2 \\
2 \\
2 \\
2 \\
0 \\
5 \\
15 \\
15\end{array}$ & $\begin{array}{l}46 \\
84 \\
71 \\
72 \\
15 \\
33 \\
30 \\
21 \\
28 \\
26 \\
11 \\
15 \\
39 \\
45 \\
16 \\
26 \\
28 \\
51\end{array}$ & $\begin{array}{l}(13) \\
(24) \\
(20) \\
(20) \\
(4) \\
(9) \\
(8) \\
(7) a \\
(8) \\
(7) \\
(4) a \\
(4) \\
(11) \\
(14) \mathrm{c} \\
(6) \mathrm{d} \\
(14) \mathrm{b} \\
(52) \mathrm{e} \\
(94) \mathrm{e}\end{array}$ & $\begin{array}{r}33 \\
68 \\
55 \\
86 \\
19 \\
16 \\
37 \\
13 \\
24 \\
29 \\
11 \\
9 \\
40 \\
40 \\
7 \\
51 \\
43 \\
72\end{array}$ & $\begin{array}{l}(11) \\
(24) \\
(19) \\
(30) \\
(7) \\
(6) \\
(13) \\
(6) a^{1} \\
(8) \\
(10) \\
(5) a^{1} \\
(3) \\
(11) \\
(16) c^{1} \\
(4) d^{1} \\
(22) b^{1} \\
(49) \mathrm{e}^{1} \\
(82) \mathrm{e}^{1}\end{array}$ \\
\hline
\end{tabular}

The total numbers of patients differ from $n=355$ and $n=289$ in some instances. These are shown by superscripts. The numbers are a297, $a^{\prime} 232$, b216, b'230, c328, c'252, d270, d'195, e54, e $\mathrm{e}^{1} 72$.

Table 3 Analysis of the prevalence of $H L A-D R$ antigens in the current study and the study by Begin et al ${ }^{21}$

\begin{tabular}{|c|c|c|c|c|c|c|}
\hline \multirow{2}{*}{$\frac{H L A}{D R}$} & \multicolumn{2}{|c|}{ Begin et al ${ }^{21}$} & \multicolumn{2}{|c|}{ The current study } & \multicolumn{2}{|l|}{ Total } \\
\hline & $\begin{array}{l}A W \\
(n=32)\end{array}$ & $\begin{array}{l}A S \\
(n=40)\end{array}$ & $\begin{array}{l}A W \\
(n=17)\end{array}$ & $\begin{array}{l}A S \\
(n=24)\end{array}$ & $\begin{array}{l}A W \\
(n=49)\end{array}$ & $\begin{array}{l}A S \\
(n=64)\end{array}$ \\
\hline $\begin{array}{l}1 \\
2 \\
3 \\
4 \\
5 \\
7\end{array}$ & $\begin{array}{ll}21 & (66) \\
10 & (31) \\
14 & (44) \\
17 & (53) \\
27 & (84) \\
38 \star & \end{array}$ & $\begin{aligned} 28 & (70) \\
22 & (55) \\
3 & (8) \\
14 & (35) \\
11 & (28) \\
44^{\star} & \end{aligned}$ & $\begin{array}{ll}4 & (24) \\
4 & (24) \\
1 & (6) \\
4 & (24) \\
5 & (29) \\
2 & (12)\end{array}$ & $\begin{array}{ll}6 & (25) \\
4 & (16) \\
5 & (21) \\
6 & (25) \\
5 & (21) \\
5 & (21)\end{array}$ & $\begin{array}{ll}25 & (51) \\
14 & (29) \\
15 & (31) \\
21 & (43) \\
32 & (65)\end{array}$ & $\begin{aligned} 34 & (53) \\
26 & (41) \\
8 & (13) \\
20 & (32) \\
16 & (25) \dagger\end{aligned}$ \\
\hline
\end{tabular}

Numbers in parentheses are percentages.

* Obviously these figures were misprinted because the frequencies exceed the total number of patients.

tRR $=2 \cdot 6,(95 \%$ CI $1 \cdot 6-4 \cdot 2) ; \chi_{Y}^{2}=16 \cdot 8 ; p_{\text {corr }}<0 \cdot 02$. 
suggested an increase in this antigen in those with advanced asbestosis compared with an AW group. Only one of the previous studies had investigated class II; that of Begin et $a l^{21}$ who recently reported the results for HLA-D 1-7 only (table 3).

The results obtained by analysis of the combined data from several studies showed no difference between AS and AW patients except that in the combined analysis of this study and that of Begin et $a l^{21}$ the prevalence of HLA-DR5 was higher in AW compared with AS patients suggesting that it is associated with resistance to developing asbestosis.

Three possible reasons for the inconsistency of the results between studies are as follows: firstly, asbestosis in previous studies was excluded on the basis of clinical and chest radiographic grounds. Since the introduction of HRCT, studies have shown that 15$30 \%$ of patients with pulmonary densities of less than $1 / 0$ on chest radiography have evidence of asbestosis on HRCT. ${ }^{33}$ Those patients would have been classified as AW in earlier studies. Secondly, some patients in the exposed group may later develop asbestosis, cancer, and mesothelioma, hence classifying this group as AW may be correct only for the time of assessment. Thirdly, the level of significance used differed between studies. Whereas most earlier studies took the conventional $p<0.05$ as significant, recent ones corrected the significance level for the number of analyses undertaken.

Svejgaard $e t$ al suggested that two major types of error exist when investigating the prevalence of HLAs. A type I error, the most common, is the assumption of a true association when in fact one does not exist. Conversely, a type II error is rejection of the hypothesis of an association where one exists. The method of statistical analysis is crucial in minimising both types of error. Fisher's exact test when applicable or $\chi^{2}$ with continuity (Yates) correction are the two methods commonly used to compare the prevalence of HLA-antigens between disease and control groups. ${ }^{30}$ Because of the high number of antigens, the possibility of obtaining significant results by chance with conventional $p<0.05$ is fairly high. Woolf ${ }^{35}$ suggested correcting the significance level by multiplying ( $p$ ) by the number of analyses undertaken and accepting the results as significant when the corrected $p\left(p_{\text {corr }}\right)$ is less than $<0.05$.

In the current study $\mathrm{p}$ was corrected according to the method of Sidak ${ }^{31}$ and Dunn ${ }^{32}$; and $p_{\text {corr }}<0.05$ was accepted as the significance level.

Pack-years of cigarette smoking in AS and AS-CA patients were higher than in $\mathrm{PD}$ and $\mathrm{AW}$ patients, whereas the duration of exposure to asbestos and time since first exposure did not differ between types of asbestos related disease. These results are consistent with several studies that have found an increase in radiographic opacities suggestive of asbestosis in asbestos workers who smoked compared with those who did not. ${ }^{36-38}$

In conclusion, our data show no significant associations between types of HLA and types of asbestos related disease by data from this study and a previously reported study combined suggest a possible protective effect of HLA-DR5 against asbestosis.

We thank Dr C Darke for his valuable assistance in preparing the manuscript.

Requests for reprints to Dr R M Rudd, The London Chest Hospital, Bonner Road, London E2 9JX.

1 Becklake MR. Asbestos-related disease of the lung and other organs: their epidemiological implications for clinical practice. Am Rev Respir Dis 1976;114:187.

2 Becklake MR. Lung structure as a risk factor in adverse pulmonary responses to asbestos exposure. Am Rev Respir Dis 1983;128:385-8.

3 Mossman BT, Gee JBL. Asbestos related diseases. N Engl J Med 1989;320:1721-30.

4 Turner-Warwick $M$, Parker WR. Circulating rheumatoid and antinuclear factors in asbestos workers. $B M J$ 1970;3:492-5.

5 Huuskonen MS, Rasanan JA, Karkonen H, Asp S. Asbestos exposure as a cause of immunological stimulation. Scand $J$ Respir Dis 1978;59:326-32.

6 Doll NJ, Diem JE, Jones RN, Rodriguez M, Bozelka BE. Humoral immunologic abnormalities in workers exposed to $\mathrm{A}$ cement dust. J Allergy Clin Immunol 1983;72:509-12.

7 Anton-Culver $\mathrm{H}$, Culver BD, Kurosaki T. Immune response in shipyard workers with $\mathrm{X}$ ray abnormalities consistent with asbestos exposure. $\mathrm{Br} J$ Ind Med 1988;45:464-8.

8 Pernis B, Vigilani EC, Selikoff IJ. Rheumatoid factor in serum of individuals exposed to asbestos. Ann N Y Acad Sci 1965;132. 112-20.

9 Lange A, Smolik R, Zatansti W, SZymanska J. Autoantibodies and serum immunoglobulin levels in asbestos workers. Int Arch Arbeitsmed 1974;32:313-25.

10 Stansfield D, Edge JR. Circulating rheumatoid factors and antinuclear antibodies in shipyard asbestos workers with pleural plaques. British Journal of Diseases of the Chest 1974; 68:166-70.

11 Kagan E, Solomon A, Cochrane JC. Immunological studies of patients with asbestosis: II. Studies of circulating lymphoid cell numbers and humoral immunity. Clin Exp Immunol 1977;28:268-75.

12 Rossi GA, Szapiel S, Ferrans VJ, Crystal RG. Susceptibility to experimental interstitial lung disease is modified by immuneand non-immune-related genes. Am Rev Respir Dis 1987; 135:448-55.

13 Brewerton DA, Caffrey M, Hart FD, James DCO, Nicholas A, Sturrock RD. Ankylosing spondylitis and HLA-27. Lancet 1973;i:904-7.

14 Merchant JA, Klauda PT, Soutar CA, Parkes WR, Lawler SD. The HLA system in asbestos workers. BMJ 1975;1:189.

15 Matej H, Lange A, Smolik R. HLA antigens in asbestosis. Arch Immunol Ther Exp 1977;25:489-91.

16 Evans C, Lewinsohn H, Evans J. Frequency of HLA Antigen in asbestos workers with and without pulmonary fibrosis. $B M J 1977 ; 1: 603-5$.

17 Gregor A, Singh S, Turner-Warwick M, Lawler S. Parks WR. The role of histocompatibility antigen HLA in asbestosis. British Journal of Diseases of the Chest 1979;73:245-51.

18 Huuskonen MS, Tilikainen A, Alanko K. HLA-B18 Antigens and protection from pulmonary fibrosis in asbestos workers. British Journal of Diseases of the Chest 1979;73:253-9.

19 Darke C, Wagner M, McMillan G. HLA-A and B antigen frequencies in an asbestos exposed population with normal and abnormal chest radiograph. Tissue Antigens 1979;13: 228-32.

20 Vergnaud MC, Petiot JF, Griveau AM, Boulier A, Lemenager J Etude des relations entre le system HLA at l'appaition d'une fibrose asbestosique dans un groupe de travailleurs exposes a 
l'amiante. Poumon et la Coeur 1983;39:283-6.

21 Begin R, Menard H, Decarie F, St-Sauveur A. Immunogenetic factors as determinant of asbestosis. Lung 1987;165:159-63.

22 Libby DM, Gibofsky A, Fotino M, Waters SJ, Smith JP. Immunogenetic and clinical findings in idiopathic pulmonary fibrosis. Am Rev Respir Dis 1983;127:618-22.

23 International Labour Office: Guidelines for those of ILO international classification of radiographs for pneumoconiosis. Geneva: ILO, 1980. (Occupational safety and health series No 22.)

24 Amos DB, Pool P. HLA typing. In: Rose NR, Friedman HS, eds. Manual of clinical immunology. Washington, DC. American society for microbiology, 1976:797-804.

25 Gibofskey A, Winchester RJ, Patarroyo M, Fotino M, Kunkel HG. Disease association of the Ia-like human alloantigens. Contrasting patterns in rheumatoid arthritis and systemic lupus erythematosus. $J \operatorname{Exp} M e d$ 1978;148:1728-32.

26 Terasaki PI. Histocompatibility testing. Los Angeles: UCLA Tissue Typing Laboratory, 1979: 18-20, 355, 509-511, 938.

27 Vartdal F, Gandernack G, Fundernud S, Bratile A, Lea T, Ugelstad J, Thorsby E. HLA class I and II typing using cells positively selected from blood by immunomagnetic isolation-a fast and reliable technique. Tissue antigens 1986; 28:302-12

28 Rose HM, Ragan C, Pearce E, Lipman MO. Differential agglutination of normal and sensitized sheep erythrocytes by sera of patients with rheumatoid arthritis. Proc Soc Exp Biol Med 1948;68:1.

29 Singer JM, Plotz CM. The latex fixation test. I. Application to the serologic diagnosis of rheumatoid arthritis. Am J Med 1956;21:888-93.
30 Svejgaard A, Jersild C, Staub Nielson L, Bodmer WF. HLA-A Antigens and disease - Statistical and genetic considerations. Tissue Antigens 1974;4:94-105.

31 Sidak Z. Rectangular confidence regions for the means of multivariate normal distributions. Journal of The American Statistical Association 1967;62:626-33.

32 Dunn OJ. On multiple tests and confidence intervals. Communication in Statistics 1974;3:101-3.

33 Staples CA, Gamsu G, Ray CS, Webb WR. High resolution computed tomography and lung function in asbestos workers with normal chest radiograph. Am Rev Respir Dis 1989;139: 1502-8.

34 Lozewicz S, Renznek RH, Herdman M, Dacie JE, McLean A, Davies RJ. Role of computed tomography in evaluating asbestos related lung disease. Br J Ind Med 1989;46:777-81.

35 Woolf $\mathbf{B}$. On estimating the relation between blood group and disease. Ann Hum Genet 1955;19:251-3.

36 Weiss W. Cigarette smoking, asbestos, and pulmonary fibrosis. Am Rev Respir Dis 1971;104:223-7.

37 Weiss W, Theodas PA. Pleuropulmonary disease among asbestos workers in relation to smoking and type of exposure. J Occup Med 1978;20:341.

38 Lilis R, Selikoff IJ, Lerman Y, Seidman H, Gelb SK. Asbestosis: Interstitial pulmonary fibrosis and pleural fibrosis in a cohort of asbestos insulation workers: Influence of cigarette smoking. Am J Ind Med 1986;10:459-70.

Accepted 17 February 1992

\section{Correspondence and editorials}

The British Journal of Industrial Medicine welcomes correspondence relating to any of the material appearing in the journal. Results from preliminary or small scale studies may also be published in the correspondence column if this seems appropriate. Letters should be not more than 500 words in length and contain a minimum of references. Table and figures should be kept to an absolute minimum. Letters are accepted on the understanding that they may be subject to editorial revision and shortening.

The journal now also publishes editorials which are normally specially commissioned. The Editor welcomes suggestions regarding suitable topics; those wishing to submit an editorial, however, should do so only after discussion with the Editor. 